\title{
Knock-Down of Id1 and Id3 Proteins Induces Apoptosis in Human Colon Carcinoma (HCT116) Cells
}

\author{
Foster Kyei (Corresponding author) \\ Lecturer, College of Agriculture and Natural Sciences, School of Biological Sciences \\ Department of Molecular Biology and Biotechnology, Rm B.2-22 \\ University of Cape Coast, Cape Coast, Ghana \\ E-mail: fkyei@ucc.edu.gh
}

Received: December 2, 2014 Accepted: December 16, 2014

doi:10.5296/jbls.v6i1.6712ＵRL: http://dx.doi.org/10.5296/jbls.v6i1.6712

\begin{abstract}
Id (Inhibitor of differentiation) proteins belong to the Helix-Loop-Helix (HLH) group of transcription factors and they are characterized by the absence of their DNA-binding domain. Id proteins are involved in cellular processes. These biological roles include cell growth, differentiation, senescence, apoptosis, angiogenesis and neoplastic transformation. This work aimed at investigating the consequences of down-regulating Id proteins on growth and pro-apoptotic functions in an in vitro model using HCT116 by siRNA gene knock-down. This objective was achieved by using antisense oligonucleotides complementary to Id1, Id 2 and Id 3 mRNA on human epithelial colon carcinoma cell line (HCT116). Silencing of Id1 and Id3 in HCT116 resulted in widespread cell death but not S-phase arrest. Interestingly, knock-down of Id 2 neither resulted in induction of apoptosis nor cell growth arrest. However, since it was able to reduce viable cell populations of HCT116 at $48 \mathrm{~h}$ post-transfection, it may imply that cell death and growth arrest following down-regulation of Id2 may occur via a different mechanism. These observations suggest that Id 1 and Id 3 could provide some therapeutic opportunities to cure colonic cancers.
\end{abstract}

Keywords: Down-regulation, Knock-down, Neoplastic, Deregulation, Carcinoma, Antisense, Oligonucleotides.

\section{Introduction}

Id proteins belong to the Helix-Loop-Helix (HLH) proteins and are involved in the coordinate regulation of gene expressions which regulate cell differentiation and lineage commitment in 
most organisms (Norton, 2000). Id proteins (Inhibitor of differentiation) have no DNA binding domain. The biological functions of Id proteins are achieved by associating with the ubiquitous E proteins and thereby preventing them from binding DNA or other transcription factors. Four members of the Id family of proteins have been identified in vertebrates namely; Id1, Id2, Id3 and Id4 (Norton, 2000). Id proteins have been shown to regulate molecular networks and cellular processes. These biological roles include cell growth, differentiation, senescence, apoptosis, angiogenesis and neoplastic transformation (Sikder et al., 2003).

The cell cycle is regulated by Id proteins by regulating the transcription of several target genes and also by direct association with non-bHLH proteins. Literature available suggests that inappropriate entry into S-phase of the cell cycle is associated with apoptosis suggesting that these two cellular activities are coordinately regulated (Askew et al., 1991; Wagner et al., 1994). Research shows that many genes have products that regulate cell cycle progression and also play a pivotal role in the modulation of apoptosis. Here, a model in which activation of the cell death pathway is due to a conflict between growth-promoting and growth-inhibitory signals is being emphasized (Hiebert et al., 1995).

Id proteins play a role in the regulating of cell growth and differentiation when over-expressed and have also been implicated to induce malignant transformation (Wilson et al., 2001). It has also been shown that balance between a cell's complement of bHLH and Id proteins plays a vital role in determining cell fate commitments of growth and differentiation and down-regulation of Id proteins results in exit from cell cycle and differentiation (Norton, 2000). It has also been established that there exists a correlation between tumour invasiveness and Id expression (Sikder et al., 2003). Deregulated expression of Id genes has been cited in tumour cell lines from lungs, colon, and pancreas and also in both neuronal and astrocytic tumour lines of the nervous system (Israel et al., 1999). Deregulation of Id expression also occurs in some primary human tumours such as seminomas, mammary tumours, pancreatic adenocarcinomas, squamous cell carcinomas and mammary tumours. Wilson et al., (2001) observed that tumour tissues compared with normal intestinal mucosa show high levels of Id1, Id2 and Id3 proteins. They also argued that expression of Id genes correlates with both mitotic index and p53 expression level. Recent evidence suggests that Id 1 and Id3 play pivotal roles in regulating developmental and postnatal angiogenesis (Nishiyama et al., 2005).

Complete loss of Id 1 and Id 3 genes resulted in vascular malformation in the forebrain resulting in brain hemorrhage (Lyden et al., 1999). With partial loss of Id1and Id3 genes, neo-angiogenesis is blocked in tumor xenografts and spontaneous tumors (Ruzinova et al., 2003). Ectopic expression of Id 1 in endothelial cells enhanced angiogenicity in both in vitro and in vivo angiogenesis models (Nishiyama et al., 2005). Literature available also suggests that down-regulation of Id proteins in colorectal adenocarcinoma cell lines by antisense oligonucleotides blockade resulted in reduction of growth (Wilson et al., 2001). Id function is involved in growth and angiogenesis of tumour cells and its regulation at intracellular levels with small-molecule-based inhibitors of these proteins might result in the development of useful drugs to treat human cancers (Lin et al., 2000). These findings have raised the hopes that the Id proteins could be a target for cancer therapy. As outlines above, it is evident that Id proteins play significant roles in inducing malignant transformation when ectopically 
over-expressed and also arrest growth upon down-regulation in both cell lines and primary models. However, knowledge of the molecular mechanisms that modulate the function and control of Ids in malignant cells and angiogenesis is limited. Hence this work investigated the consequences of loss-of-function of Id protein on pro-apoptotic functions using siRNA gene knock-down. This objective was achieved by using antisense oligonucleotides complementary to Id1, Id2 and Id3 mRNA on human epithelial colon carcinoma cell line (HCT116).

\section{Materials and Methods}

\subsection{Adherent Cell Culture and Id Down-regulation}

Human epithelial colon carcinoma cell line (HCT116) (American Type Culture Collection, USA) were propagated in Dulbecco Modified Eagle Medium (DMEM) (Biowhittaker/Lonza, Walkersville, MD, USA) supplemented with 10\% Foetal Calf Serum (FCS) (PAA Laboratories, Austria). Cells were cultured in T25 and T75 flasks. At passaging, cells were washed in $2 \mathrm{ml}$ of sterile $1 \times \mathrm{PBS}$ and trypsinised with $1 \mathrm{ml}$ of $1 \times$ Trypsin (pre-warmed) (trypsin from GIBCO, USA and trypsin-EDTA from PAA Laboratories, Austria) and incubated in $5 \% \mathrm{CO}_{2}$ incubator at $37^{\circ} \mathrm{C}$ (Sanyo, Japan) for $5 \mathrm{~min}$. Thereafter $5 \mathrm{ml}$ of complete DMEM (PAA Laboratories, Austria) was added to the flask of cells to inactivate the action of the trypsin. Cells were then plated in fresh flasks, labeled and returned into the incubator. Cells were passaged every 3 days and cultured in $5 \% \mathrm{CO}_{2}$ incubator to maintain cell viability. Evidence of contamination was monitored to ensure that cells were always healthy. In 24 -well plates, $8 \times 10^{4} /$ well of HCT116 cells were transfected with control siRNA (30 nM), Id1 siRNA (30 nM), Id2 siRNA (30 nM), and Id3 siRNA (30 nM). For Id siRNA knock-down, the old medium on cells in a 24-well plate was carefully removed. Approximately $0.5 \mathrm{ml}$ of fresh serum-containing medium (without antibiotics) was added onto the cells and returned into the incubator. $2.25 \mu 1$ of siRNA ( $20 \mu \mathrm{M}$ stock) was mixed in $35 \mu \mathrm{l}$ of serum free medium by carefully pipetting one time in one Eppendorf tube. In a separate Eppendorf tube, 3 ul of Nanofectin siRNA reagent (PAA Laboratories, Austria) was mixed in $40 \mu 1$ serum free medium by carefully pipetting one time. The two solutions were combined without any further mixing (because shear stress may destroy the siRNA-Nanofectin siRNA complex). The mixture was incubated at room temperature for $20 \mathrm{~min}$. Approximately $25 \mu \mathrm{l}$ of siRNA-Nanofectin-siRNA-mix was added drop-wise evenly onto the cells in each well (making a final concentration of the siRNA to be $30 \mathrm{nM}$ ). The plate was returned into the $5 \% \mathrm{CO}_{2}$ at $37^{\circ} \mathrm{C}$. After $3.5 \mathrm{~h}$ post-transfection, the medium on cells was carefully removed and replaced with $0.5 \mathrm{ml}$ of fresh complete medium. During the siRNA transfections, the Id siRNAs were incubated on ice and both RNAse free Eppendorf tubes and Gilson tips were used throughout the transfections. Id1, Id 2 and Id 3 were then transiently silenced by gene specific siRNA (Table 1). Transfection efficiency was examined by BX-41 fluorescence microscopy (Olympus, Tokyo). $8 \times 10^{4} /$ well of HCT116 cells were propagated in 12-well plates and transfected with $30 \mathrm{nM}$ fluorescent siRNA (QIAGEN, Netherlands) with Nanofectin siRNA reagent (PAA Laboratories, Austria) and Hoechst-stained thereafter at $24 \mathrm{~h}$ post-transfection to estimate the transfection efficiency. The efficiency of fluorescent siRNA transfection after $24 \mathrm{~h}$ was approximately $100 \%$.

Table 1. siRNA duplex Oligoribonucleotides for Id1, Id2 and Id3 proteins 


\begin{tabular}{|l|c|lr|}
\hline Id Protein & Primer Name & RNA \\
\hline Id1 & ID1HSS142592 & GCA AGG UGA GCA AGG UGG AGA UUC U \\
& ID1HSS142592 & AGA AUC UCC ACC $\quad$ UUG CUC ACC UUG C \\
\hline Id2 & ID2HSS105176 & ACG UCA UCG ACU ACA UCU UGG ACC U \\
\hline Id3 & ID2HSS105176 & AGG UCC AAG AUG UAG UCG AUG ACG U \\
\hline & ID3HSS142595 & GGC ACU CAG CUU AGC CAG GUG GAA A \\
\hline
\end{tabular}

\subsection{Cell Proliferation Assay}

MTT (3-(4, 5-Dimethylthiazol-2-yl)-2, 5-diphenyltetrazolium bromide) assay (Sigma-Aldrich, USA) was used to evaluate the proliferative activity of HCT116. In a 24-well plate, $25 \mu 1$ of the MTT working stock $(10 \mathrm{mg} / \mathrm{ml})$ was added directly onto cells grown in $0.5 \mathrm{ml}$ of complete growth medium. The plate was swirled gently to ensure that the MTT was uniformly mixed. The plate was returned into the $5 \% \mathrm{CO}_{2}$ incubator at $37^{\circ} \mathrm{C}$ for four hours. The MTT containing medium was removed by tilting the plate towards one edge and completely removing all traces of MTT-containing medium with p200 Gilson's pipette being very careful not to touch the cell monolayer. The formazin formed was then solublised by pipetting down onto the cells $0.6 \mathrm{ml}$ of Dimethyl Sulfoxide (DMSO) (Fisher Scientific, USA). The plate was again returned into the incubator for $20 \mathrm{~min}$. The cells were harvested with p1000 Gilson's pipette and the contents transferred into Eppendorf tubes. The cell suspension was spun at $12000 \mathrm{rpm}$ for $5 \mathrm{~min}$ in an angular spectrafuge (Labnet International, Inc., USA) to remove cell debris. The absorbance was measured spectrophotometrically from a micro-plate reader (VERSAmax turnable micro-plate reader, Molecular Devices, USA) at $560 \mathrm{~nm}$ by adding $100 \mu \mathrm{l}$ of the spun harvested cells into a 96-well plate. Experiments were performed in quadruplicate, and the proliferative activity was calculated as the mean \pm standard deviation (SD) of the quadruplicate wells divided by that of the controls.

\subsection{Cell Cycle Assay}

A more robust approach to cell cycle profiling was adopted by measuring the DNA content of cells (integrated intensity) using Hoechst dye in conjunction with EdU. The EdU imaging kit ("Click-It EdU", Invitrogen, USA) was used to detect the cycling HCT116. Here in 12-well plate, $8 \times 10^{4} /$ well of cells were washed twice in $200 \mu 1$ of $1 \times$ PBS and replaced with $1 \mathrm{ml}$ of fresh complete growth medium and $3 \mu \mathrm{l}$ of EdU (component A) was added and swirled gently. The plate was returned into the incubator for $1.5 \mathrm{~h}$. The growth medium was then removed and rinsed in $200 \mu 1$ of $1 \times$ PBS. The PBS wash was then discarded. Cells were trypsinised thereafter in $50 \mu \mathrm{l}$ of trypsin. $1 \mathrm{ml}$ of fresh complete medium was used to harvest the cells. Cells were spun at $7000 \mathrm{rpm}$ for $5 \mathrm{~min}$ and the supernatant was removed and discarded. Cells were then 
resuspended and washed once in $500 \mu \mathrm{l}$ of complete medium. During the fixation, cells were resuspended in $100 \mu \mathrm{l}$ of PBS followed by addition of $100 \mu 1$ of $8 \%$ PFA (Sigma-Aldrich, USA) to fix for $15 \mathrm{~min}$ (4\% final PFA concentration). The fixative was spun-out at $7000 \mathrm{rpm}$ for 5 min. Supernatant was removed thereafter. Cells were washed by resuspending in $50 \mu 1$ of PBS and spun again at $7000 \mathrm{rpm}$ for $5 \mathrm{~min}$. Supernatant was removed. The cells were resuspended and stained in $500 \mu \mathrm{l}$ of $8 \mu \mathrm{g} / \mathrm{ml}$ Hoechst 33258 fluorochrome stain (Sigma-Aldrich, USA) contained in $1.5 \mathrm{ml}$ Eppendorf tube. Cells were incubated in $37^{\circ} \mathrm{C}$ water-bath for $45 \mathrm{~min}$. Cells were then washed once by resuspending in $1 \mathrm{ml}$ of $1 \times \mathrm{PBS}$. Thereafter cells were then spun at $7000 \mathrm{rpm}$. The PBS was carefully discarded. Cells were then resuspended in $10 \mu \mathrm{l}$ of PBS and transferred onto silanized slides to make smears (with Gilson's). At this stage the cells were dried for $10 \mathrm{~min}$ in $35^{\circ} \mathrm{C}$ bacterial culture incubator (Brunswick Scientific, USA) and rehydrated in $1 \times \mathrm{PBS}$ for 15 min contained in washing/staining tank. Thereafter the cells were washed 3 times in PBS (each wash in fresh PBS by dipping slide holder in and out of the PBS solution) and a ring of vaseline was applied around the cells. Cells were incubated in $50 \mathrm{ul}$ of EdU cocktail reaction mix for 45 min. Cells were washed twice in PBS (as described above). The slide was wiped carefully with $70 \%$ ethanol and mounted in Mowiol mountant (Calbiochem, Germany). Images were captured thereafter with BX-41 fluorescent microscope (Olympus, Tokyo) for automated image analysis using Image-J software, CellProfiler software and CellProfiler analyst to measure the integrated intensity of Hoechst stained nuclei and the mean intensity of EdU positive cells. Using the tools in CellProfiler Analyst, cell cycle profiles were generated and the various sub-populations were quantified. At least 50,000 cells were scored for cell cycle analysis in 3 replicates. To confirm the results obtained with the Hoechst-EdU regime, Propidium Iodide (PI) (Sigma-Aldrich, USA) was also tested. Cell cycle analysis was also done using PI stain on cells. Cells were seeded in 12-well plates and transfected with the Nanofectin siRNA reagent. At both 24 and $48 \mathrm{~h}$ post-transfections, the medium on cells was carefully harvested into $1.5 \mathrm{ml}$ siliconised Eppendorf tubes. Approximately $100 \mathrm{ul}$ of trypsin was added onto the cells and returned into the $37^{\circ} \mathrm{C}, 5 \% \mathrm{CO}_{2}$ incubator. During the incubation period, the harvested medium was spun at $2000 \mathrm{rpm}$ for $5 \mathrm{~min}$. The supernatant was then used to harvest the trypsinised cells. The cells were again centrifuged at $2000 \mathrm{rpm}$ for $5 \mathrm{~min}$ in the Beckman horizontal rotor (Beckman, USA). The supernatant was carefully removed and cells were carefully washed once in $0.5 \mathrm{ml}$ of PBS. Cells were then fixed in $0.5 \mathrm{ml}$ of $70 \%$ ethanol for $30 \mathrm{~min}$ at $4^{\circ} \mathrm{C}$. Cells were spun at $2000 \mathrm{rpm}$ for $5 \mathrm{~min}$ in the Beckman horizontal rotor followed by careful removal of the supernatant. Thereafter cells were washed 2 times in $0.5 \mathrm{ml}$ of ice-cold PBS. After the second wash, the supernatant was carefully removed. Finally the cells were stained in $200 \mu \mathrm{l}$ of Propidium Iodide $(50 \mu \mathrm{g} / \mathrm{ml})$ for $30 \mathrm{~min}$ in the presence of $50 \mu 1 \mathrm{RNAse} A(100 \mu \mathrm{g} / \mathrm{ml})$ (Sigma-Aldrich, USA). The RNAse was pre-incubated for $5 \mathrm{~min}$ at room temperature before the PI was added. At the end of the incubation period, cells were immediately processed through the flow cytometer. Data from the flow cytometer were analysed using WinMDI 2.9 software. Sub-populations of cells were gated and quantified from the density plots generated.

\subsection{Cell Death Analysis}

DiOC6 (3, 3'-dihexyloxacarbocyanine iodide) (Invitrogen, USA) was counter stained with PI 
to detect the proportion of apoptotic HCT116. $8 \times 10^{4} /$ well of cells were seeded in either 12 plates and transfected with Id-siRNA as described previously. At 24 or $48 \mathrm{~h}$ post-transfection, DiOC6 stain (working stock concentration of $100 \mathrm{nM}$ in growth medium) was added onto the medium on cells to make a final concentration of $50 \mathrm{nM}$. The plate was gently swirled to ensure uniform mixing. Cells were then incubated for $15 \mathrm{~min}$ in the $37^{\circ} \mathrm{C}, 5 \% \mathrm{CO}_{2}$ incubator. The medium on cells was harvested into $1.5 \mathrm{ml}$ siliconised Eppendorf tubes. Approximately $100 \mathrm{ul}$ of trypsin was added onto the cells and returned into the $37^{\circ} \mathrm{C}, 5 \% \mathrm{CO}_{2}$ incubator. During the incubation period, the harvested medium was spun at $2000 \mathrm{rpm}$ for $5 \mathrm{~min}$ in the Beckman horizontal rotor. The supernatant was then used to harvest the trypsinised cells. The cells were again centrifuged at $2000 \mathrm{rpm}$ for $5 \mathrm{~min}$ in the Beckman horizontal rotor. The supernatant was carefully removed and cells were carefully washed in $200 \mu 1$ of $1 \%$ BSA/PBS solution by resuspending. Cells were again spun at $2000 \mathrm{rpm}$. Cells were resuspended in $500 \mu \mathrm{l}$ of $1 \%$ BSA/PBS solution. Cells were incubated on ice in flow tubes and stained with PI at final concentration of $2.5 \mathrm{mg} / \mathrm{ml}$. Cells were then incubated on ice and then processed through the flow cytometer. Data from the flow cytometer were analysed using WinMDI 2.9 software. Sub-populations of cells were gated and quantified from the density plots generated.

\subsection{SDS-PAGE Protein Electrophoresis}

HCT116 cell lysates were prepared into $1.5 \mathrm{ml}$ Eppendorf tubes from 24-well plates. The cells were span at $7000 \mathrm{rpm}$ for $5 \mathrm{~min}$ in the horizontal Beckman rotor (Beckman, USA). The supernatant was carefully removed and cells were resuspended in $15 \mu 1$ of $50 \mathrm{nM}$ Tris- $\mathrm{HCl}(\mathrm{pH}$ - 6.8). $15 \mu \mathrm{l}$ of $2 \times \mathrm{SDS}$ buffer was then added to lyse the cells. Thereafter $4.2 \mu \mathrm{l}$ of $25 \times$ bromophenol blue (Sigma-Aldrich, USA) in $20 \%$ Glycerol (Fisher Scientific, USA) was added to the lysed cells and mixed thoroughly. The cell lysates were then boiled in a water bath at $95^{\circ} \mathrm{C}$ for $5 \mathrm{~min}$ and stored at $-20^{\circ} \mathrm{C}$. The polyacrylamide separating gel (15\%) was polymerized by addition of $0.02 \%$ TEMED (Sigma-Aldrich, USA) followed by $0.1 \%$ Ammonium Persulfate (APS) (Sigma-Aldrich, USA) in assembled glass plate leaving about 3 $\mathrm{cm}$ space from the top of the glass. $1 \mathrm{ml}$ of Butanol (Fisher Scientific, USA) was evenly layered onto the top of the gel and allowed to set for $30 \mathrm{~min}$ at room temperature. The layer of butanol was carefully removed and washed with deionised water. A gel comb was carefully slotted into the assembled glass plate on top of the polymerized separating gel followed by loading the stacking gel (5\%). The stacking gel was allowed to set at room temperature for $30 \mathrm{~min}$. The gel comb was carefully removed. Running buffer was poured into the gel tank filling the centre of the unit and wells. The wells were washed to remove all bubbles. The total cell lysate prepared above was heated at $95^{\circ} \mathrm{C}$ in a water bath. $6 \mu$ of each cell lysate was loaded into the wells and resolved at $120 \mathrm{~V} / 13 \mathrm{~mA}$ until the bands reach the bottom of the glass plate in running gel buffer.

\subsection{Western Blot Analysis}

Western blot analysis was performed after the gel electrophoresis. The glass plate was carefully separated and the stacking gel portion was cut out. The resulting gel was transferred into a gel sandwich, which was assembled on the anode electrode plate in the following order: 3 Whatman $^{\mathrm{TM}}$ papers (Sigma-Aldrich, USA), the transfer membrane, the gel, and another 3 


\section{Macrothink}

Whatman ${ }^{\mathrm{TM}}$ papers. The acrylamide gel containing the proteins of interest were transferred onto Polyvinylidene fluoride (PVDF) membrane (Immobilon, Millipore Inc., Germany) using a wet blotter apparatus (Bio-Rad, USA) into a blotting buffer overnight at $4^{\circ} \mathrm{C}$ with settings at $75 \mathrm{~V}, 200 \mathrm{~mA}$ and $12 \mathrm{~W}$. The following day, membranes were blocked with blocking buffer for $45 \mathrm{~min}$ at room temperature on a shaker. The membranes were incubated with primary antibody (Id1, Id 2 and Id 3 rabbit polyclonal IgG, Santa Cruz Biotechnology, USA) for $2 \mathrm{~h}$ at room temperature with gentle shaking. The membranes were then washed 3 times with washing buffer with each washing lasting for $10 \mathrm{~min}$. The washing was done with gentle shaking. The membranes were incubated with secondary antibody (anti-rabbit HRP goat, Abcam, UK) with gentle shaking at room temperature for $1 \mathrm{~h}$ followed by repeated three washes as described above. For Western blot analysis, the protein side of the membranes were incubated in western HRP substrate (Millipore Corporation, Germany) for 5 min and exposed to the autoradiography film (KODAK, USA) for various lengths of time ranging from 5 min to $30 \mathrm{~min}$. The films were developed manually with developer and fixer (KODAK, USA).

\subsection{Statistical Analysis}

Statistical analysis was carried out on data obtained from this study using the Vassar Statistical computational website (http://faculty.vassar.edu/lowry/VassarStats.html). The $P$ values were then calculated for the significance of the difference between the test and control proportions. Also student $t$-test was used to compare the significance of the difference between controls and test samples. Differences were considered to be statistically significant at $P<0.05$ (*), highly significant at $P<0.001(* *)$, very highly significant at $P<0.0001(* * *)$.

\section{Results}

\subsection{Knock-down of Id1, Id2 and Id3 Reduces Viable Cell Populations of HCT116}

By using MTT as a measure of viability, the results showed a significant reduction in the population of viable and proliferating HCT116 cells upon knocking down Id1 and Id3 proteins at both 24 and $48 \mathrm{~h}$ post-transfection at $30 \mathrm{nM}$ (Figure 1). However upon siRNA down-regulation of Id2 proteins in HCT116, there was significant reduction in population of viable cells only at $48 \mathrm{~h}$ post-transfection but not at after $24 \mathrm{~h}$ of transfection. Western blot analysis showed reduced protein levels of Id1, Id2 and Id3 (Figure 1). 

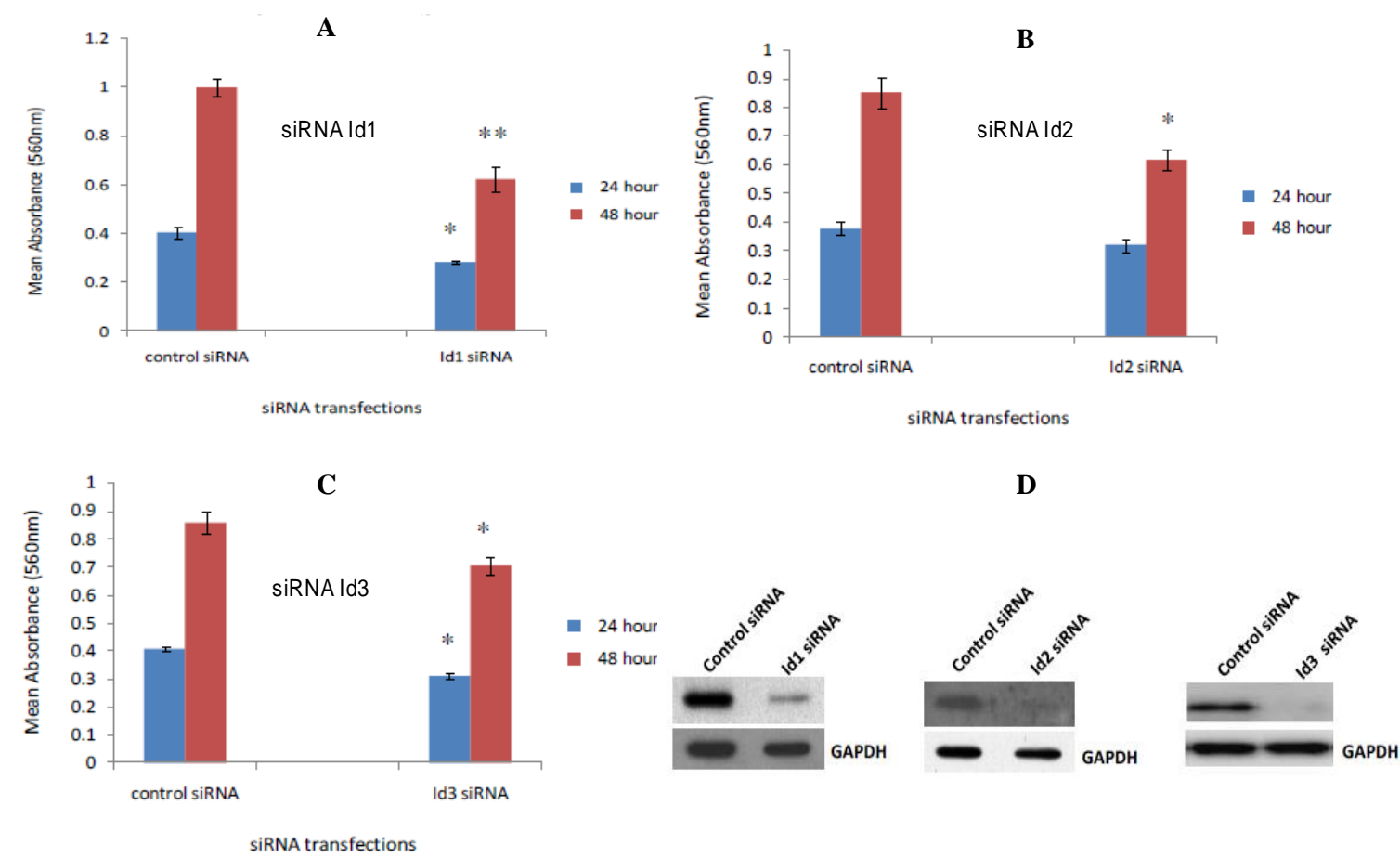

Figure 1. Cell viability analysis of HCT116 with MTT assay showing relative viable cell numbers transfected with either control siRNA or Id1 siRNA, Id2 siRNA and Id3 siRNA using Nanofectin reagent. Mean absorbance \pm S.E.M of 4 separate/independent samples. A: Knock down of Id1, B: Knock-down of Id2, C: Knock-down of Id3. Western blot analysis following siRNA knock-down of Id1-3 in HCT116 (D). GAPDH was used as loading control.

\subsection{IdI and Id3 Knock-out Induce Apoptosis in HCT116 but not Id2}

Following the observations in section 3.1 that down-regulation of siRNA Id1, siRNA Id2 and siRNA Id3 reduces population of viable HCT116 cells, an independent apoptotic marker DiOC6 was used to investigate whether the reduction in population of viable cells is as a result of cell death. 8X104/well of HCT116 cells were seeded in 12-well plates and transfected with control siRNA, siRNA Id1, siRNA Id 2 and siRNA Id3 with Nanofectin siRNA. At 24 and $48 \mathrm{~h}$ post-transfection, cells were stained with $50 \mathrm{nM}$ DiOC6 and counter-stained with PI at 2.5 $\mathrm{mg} / \mathrm{ml}$ as described previously. The results show that Id1 siRNA, Id3 siRNA significantly induce apoptosis (Figure 2) at both 24 and $48 \mathrm{~h}$ post-transfection. However the results showed that knocking down of Id2 does not induce apoptosis in HCT116 cells (Figure 2). 


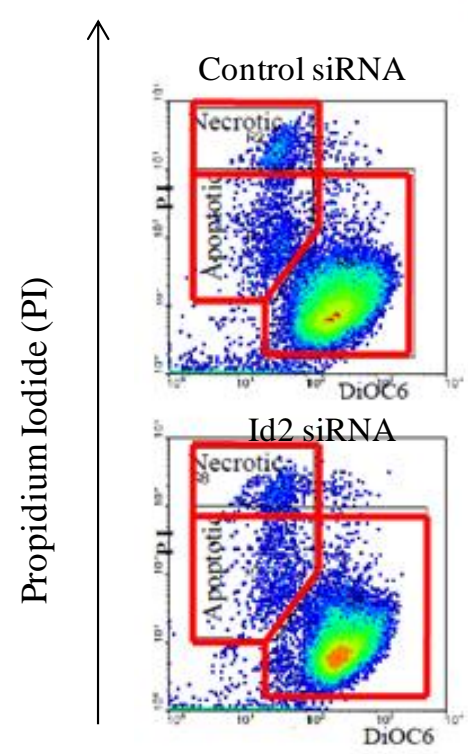

A

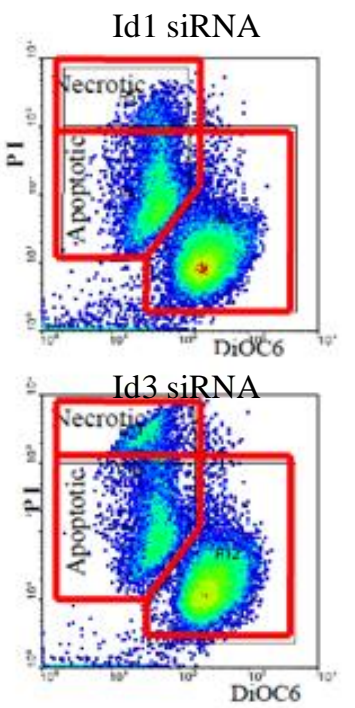

B
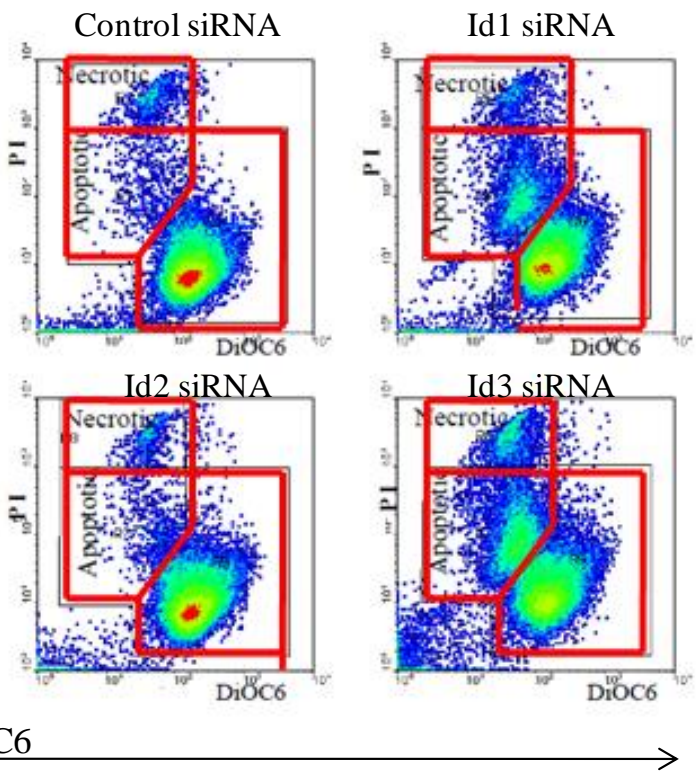

DiOC6

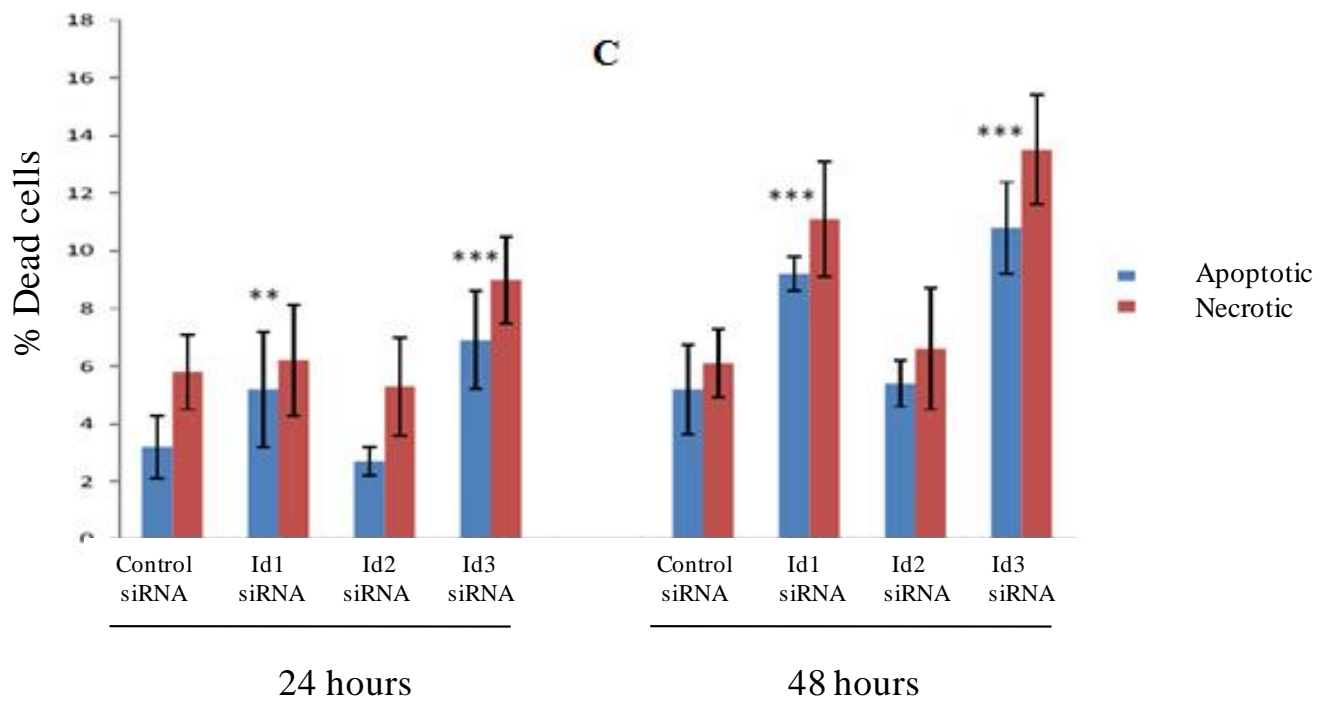

Figure 2. Flow cytometric analysis of HCT116 cells for viable, apoptotic and necrotic cell population using DiOC6 and PI following knock-down of Id1, Id2 and Id3. Cells were incubated with DiOC6 at $50 \mathrm{nM}$ for $15 \mathrm{~min}$ and counter-stained with PI at $2.5 \mathrm{mg} / \mathrm{ml}$. A:

Profiles of viable, apoptotic and necrotic cells at $24 \mathrm{~h}$ post-transfection. B: Profiles of viable, apoptotic and necrotic cells at $48 \mathrm{~h}$ post-transfection. C: Percentage apoptotic and necrotic populations at both 24 and $48 \mathrm{~h}$ of post-transfection. WinMDI 2.9 software was used to generate density profiles. Means \pm S.E.M of 3 separate independent experiments.

\subsection{Knock-down of Id2 does not Suppress S-phase Cells in HCT116}

Next was to investigate whether knocking-down of Id2 suppresses cell proliferation since it significantly reduces the population of viable HCT116 at 48 h post-transfection (section 3.1) but does not induce apoptosis (section 3.2). This would also enable an investigation into whether the reduction in viable cell numbers upon knock-down of Id 1 and Id3 is also mediated 


\section{Macrothink Institute ${ }^{T M}$}

through growth arrest. In this approach, $8 \times 10^{4} /$ well of HCT116 cells were plated in 12 -well plates and transfected with control siRNA, Id1 siRNA, Id2 siRNA and Id3 siRNA using Nanofectin siRNA reagent and processed for EdU S-phase detection at both 24 and $48 \mathrm{~h}$ post-transfection. Cells were stained with Hoechst dye for DNA content analysis. After running the cells through CellProfiler software, CellProfiler Analyst was used to generate density plots for estimation of cell cycle parameters. At both 24 and $48 \mathrm{~h}$ post-transfection, it was observed that siRNA down-regulation of Id2 does not suppress S-phase cells in HCT116. However, Id2 knock-down rather saw a significant increase in S-phase cells (Figure 3). Also, knock-down of Id1 and Id3 does not suppress S-phase cells in HCT116 but significantly promotes cell entry into S-phase (Figure 3). To validate the above results, cell cycle analysis by staining cells with PI was carried out on the HCT116 cells. The results showed no effect on reduction in proliferation following knock-down of Id1, Id2 and Id3 proteins at 24 and $48 \mathrm{~h}$ post-transfection (Figure 4). These results are in agreement with what was previously observed with EdU S-phase analysis and confirm the effect of down-regulation of Id1, Id 2 and Id3 on growth of HCT116 cells. To also confirm the widespread cell death induced by knocking down of Id1 and Id3 (section 3.2), the sub-G1 population (representing both apoptotic and necrotic cells) of the cell cycle profiles obtained from the PI staining experiment was also evaluated. This observation on down-regulation of Id 2 confirms earlier findings that Id 2 siRNA neither induces cell death nor arrests growth of HCT116 cells (section 3.2). Here it was also evident that down-regulation of Id1 and Id 3 in HCT116 induced widespread cell death at both 24 and 48 h post-transfection but not Id2 knock-down (Figure 5).
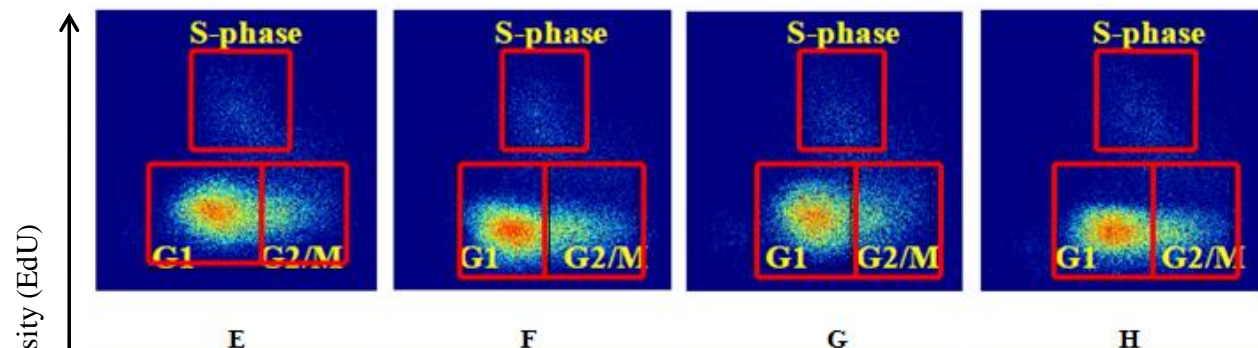

$\mathbf{F}$

G

H
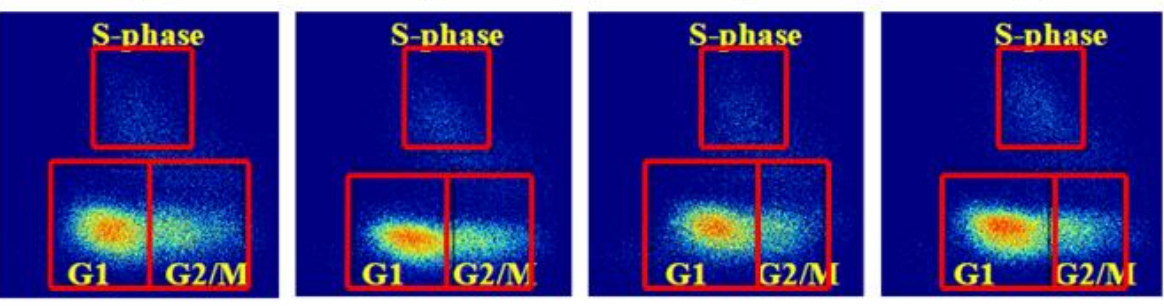

Integrated Intensity (Hoechst)
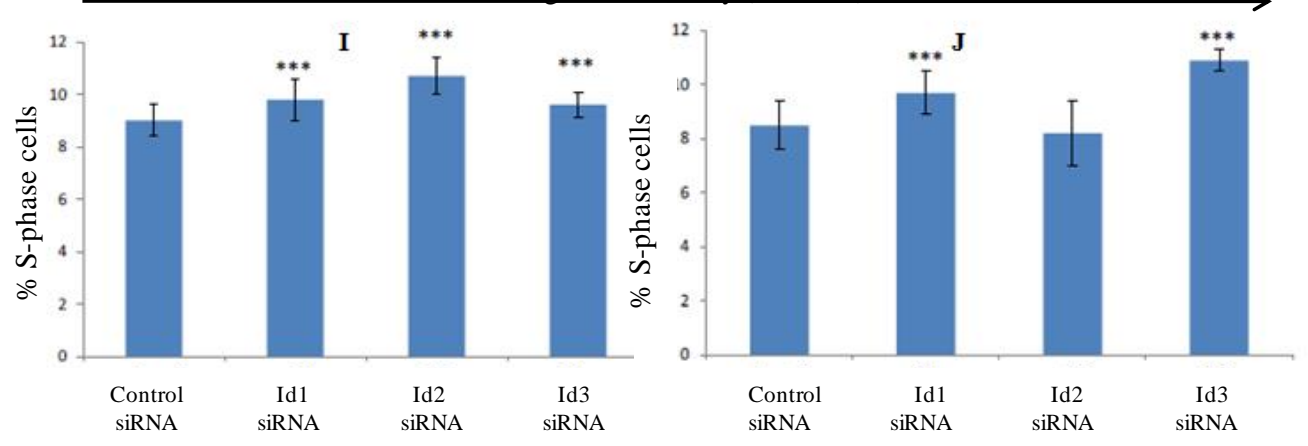


\section{Macrothink}

Figure 3. Cell cycle analysis in HCT116 showing percentage G1, S and G2/M populations generated by

CellProfiler Analyst following down regulation of Id1, Id2 and Id3 genes. Cells were stained with EdU for S-phase detection and counter stained with Hoechst dye for $45 \mathrm{~min}$. Digital images were taken and processed through CellProfiler for automated image analysis. A, B, C, and D illustrate the cell cycle profiles from control siRNA, siRNA Id1, siRNA Id2 and siRNA Id 3 respectively at $24 \mathrm{~h}$ post-transfection. E, F, G and $\mathrm{H}$ illustrate the cell cycle profiles from control siRNA, siRNA Id1, siRNA Id 2 and siRNA Id 3 respectively at $48 \mathrm{~h}$ post-transfection. I and J show the percentage S-phase cells respectively for 24 and $48 \mathrm{~h}$ post-transfection experiments. Means \pm S.E.M of 3 separate independent experiments.

A

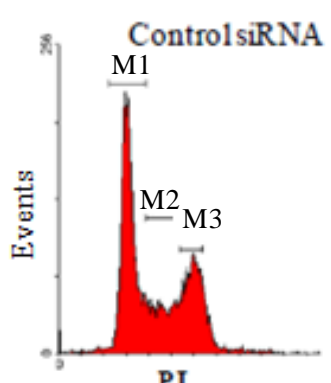

PI

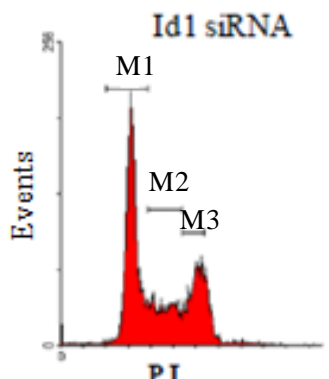

PI
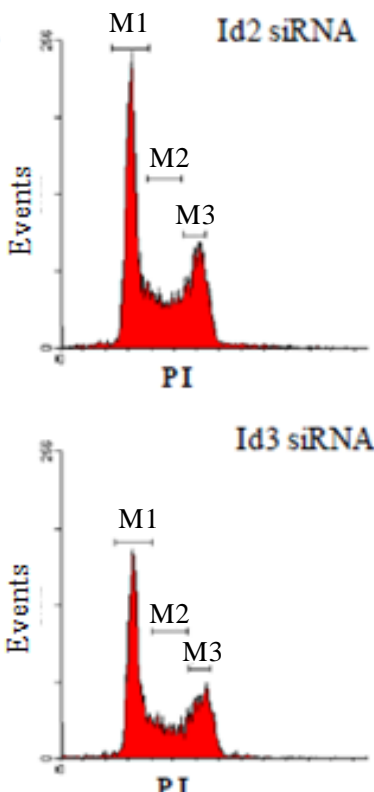

B
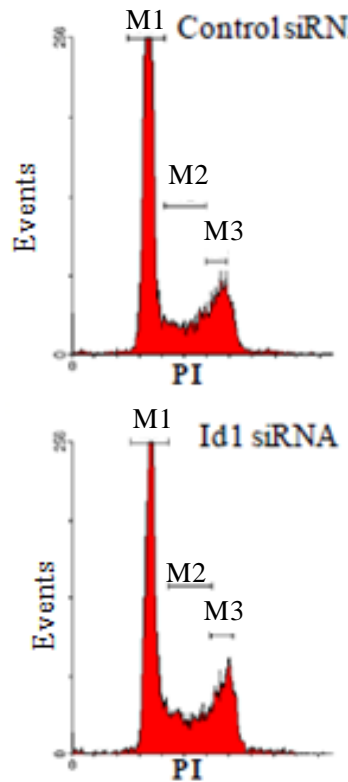

C

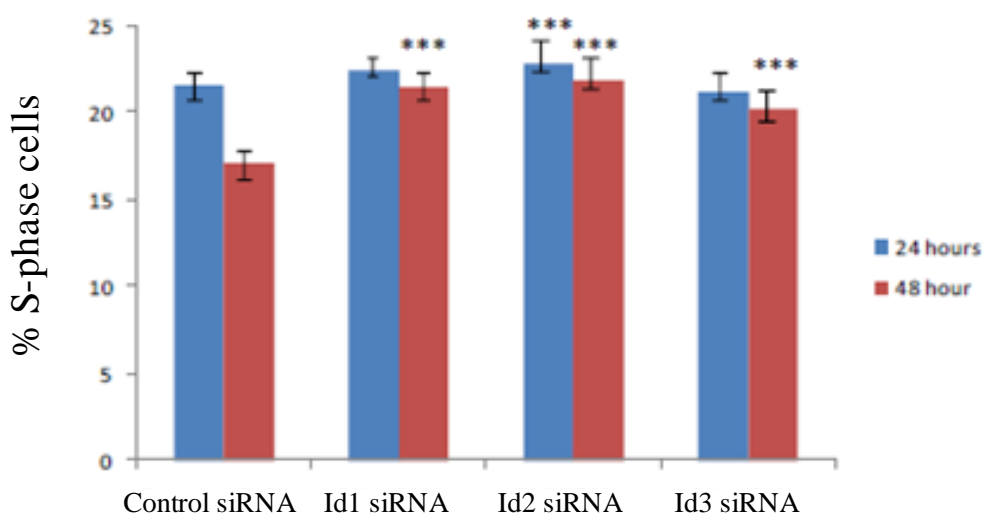

Figure 4. Flow cytometric analysis of HCT116 showing cell cycle profiles from PI $(50 \mu \mathrm{g} / \mathrm{ml})$ staining of cells upon knock-down of Id1, Id 2 and Id 3 proteins. A: Cell cycle profiles showing G1, S and G2/M cell populations at 24 h post-transfection. B: Cell cycle profiles showing G1, S and G2/M cell populations after $48 \mathrm{~h}$. C: Percentage S-phase cell population at 24 and $48 \mathrm{~h}$ post-transfection. Means \pm S.E.M of 3 separate independent experiments. 
A

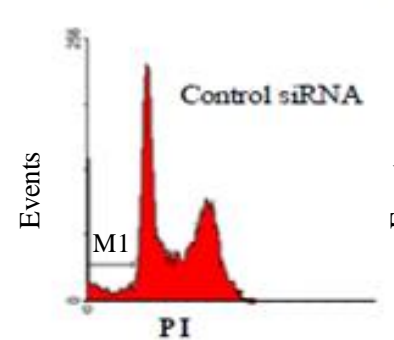

PI

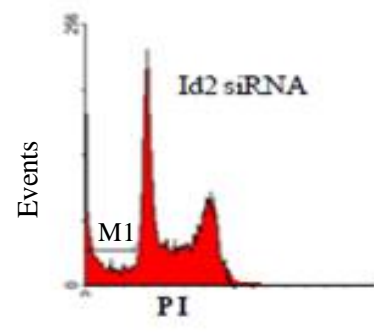

ब0

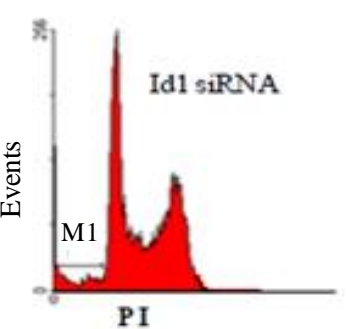

B

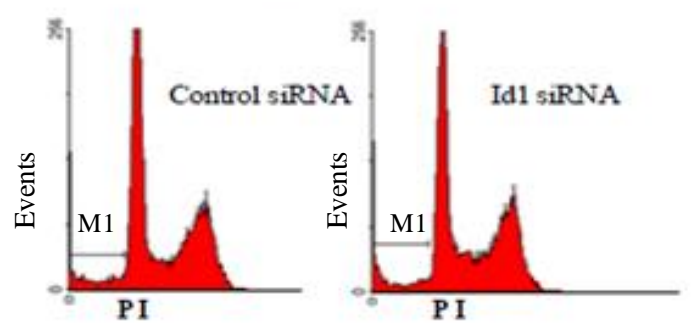

C
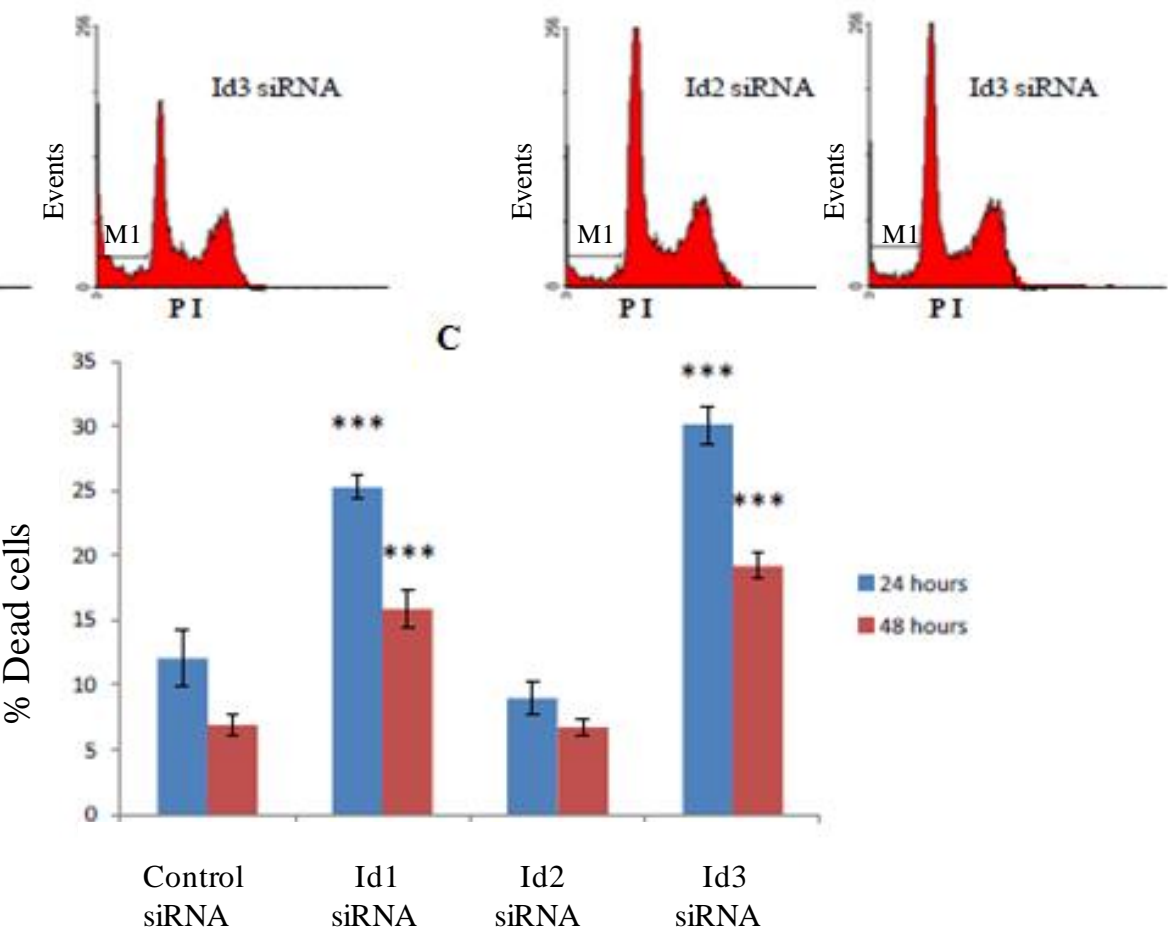

Figure 5. Flow cytometric analysis of HCT116 showing dead and viable cells from PI and DiOC6 staining of cells upon knock-down of Id proteins. A: Cell cycle profiles showing sub-G1 cell populations at $24 \mathrm{~h}$ post-transfection. B: Cell cycle profiles showing sub-G1 populations after $48 \mathrm{~h}$. C: Percentage dead cell populations at 24 and $48 \mathrm{~h}$ post-transfection. Means \pm S.E.M of 4 separate/independent samples at 24 and $48 \mathrm{~h}$ post-transfection for each transfection.

\section{Discussion}

The consequences of loss-of-function of Id protein on pro-apoptotic functions in human colon carcinoma (HCT116) cells by siRNA gene knock down were investigated. Down-regulation of Id 1 and Id3 in HCT116 showed reduction in population of viable cells at both 24 and $48 \mathrm{~h}$ post-transfection. On the other hand, knock-down of Id 2 did not result in reduction of populations of viable cells at $24 \mathrm{~h}$ post-transfection but showed reduced viable cells numbers after $48 \mathrm{~h}$ of transfection (Figure 1). Further to the above observations, cell death analysis following Id 1 and Id3 antisense Oligonucleotide blockade in HCT116 showed significant cell death (Figure 2). However, consistent with $\mathrm{Id} 2$ inability to reduce viability following 
down-regulation, knock down of Id 2 did not show evidence of apoptosis induction at both 24 and $48 \mathrm{~h}$ post-transfection (Figures 2 and 5). In relation to this, cell cycle analysis showed an activity of Id2 siRNA not able to suppress S-phase cells but rather promoted the entry into S-phase, suggesting that knock down of Id2 in HCT116 does not impair growth (Figures 3 and 4). Contrary to these observations, repression of Id 2 in HCT116 cell lines resulted in reduced proliferation and also enhanced cell death (Gray et al., 2008). Studies also show that down-regulation of Id proteins in colorectal adenocarcinoma cell lines by antisense oligonucleotides blockade resulted in reduction of growth (Wilson et al., 2001). Data on colorectal cancer cell lines show that reduction in levels of Id2 with siRNA decreased proliferation (Lasorella et al., 1996). Also, tumours derived from cells with down-regulated Id2 levels are characterised by smaller tumours with fewer metastases as opposed to those with normal levels in vivo (Gray et al., 2008). Gray and colleagues (2008) also argue that Id 2 may have opposing functions in developmental and oncogenic tissues and may also be dependent on the presence or absence of co-regulators that direct Id 2 function. The above findings suggest that HCT116 cell death following knock-down of Id 2 may occur by a different mechanism. There is a growing body of evidence supporting the role of Id proteins in tumourigenesis mechanisms. In human colorectal adenomas, deregulation of Id expression was observed indicating an up-regulation of Id expression levels during tumourigenesis of intestinal epithelium (Wilson et al., 2001). Also anti-sense inhibition of Id1 protein expression prevented invasiveness of breakdown cluster region (BCR)-Abelson leukaemia viral oncogene (ABL) driven to many organs (Fong et al., 2004; Tsuchiya et al., 2005). Studies show that double knock down of either Id1 or Id3 showed partial inhibition of VEGF-induced activation of angiogenesis and it has also been demonstrated that Id1 and Id 3 share similar promoter region sequences, and exert overlapping biochemical functions, therefore one may compensate for the other, at least partially (Sakurai et al., 2004). Research also shows that there is a correlation between Id expression and mitotic index as well as with p53 expression level in human colorectal adenocarcinomas. As a result loss of $\mathrm{p} 53$ function from the deregulation of Id protein expression in colorectal cancer, there is uncontrolled proliferation of this tumour (Wilson et al., 2001). The application of anti-sense and small interference siRNA-based techniques has shown that the two major phenotypic hallmarks of tumour aggressiveness, invasion and metastasis are disrupted when Id protein levels in tumour cells are forcibly lowered. Thus, the reduction in protein levels of both Id1 and Id3 in gastric cancer prevented metastatic dissemination to the peritoneum whilst Id1 during its inactivation in breast cancer cells inhibited invasion and metastasis to the lung.

\section{Conclusion}

The balance between a cell's complement of bHLH and Id proteins plays an important role in determining cell fate commitments of growth and differentiation and down-regulation of Id proteins results in cell cycle exit and differentiation (Norton, 2000). Literature available suggests that inappropriate entry into S-phase of the cell cycle is associated with apoptosis suggesting that these two cellular activities are coordinately regulated (Askew et al., 1991; Wagner et al., 1994). Also, many genes have products that regulate cell cycle progression and also may modulate of apoptosis. Down-regulation of Id1 and Id3 in human epithelial colon 
carcinoma cell line (HCT116) resulted in widespread cell death but not impairment of growth. Interestingly, knock-down of Id 2 did not result in induction of apoptosis; neither did it result in S-phase arrest as depicted in the DNA content analysis. This observation is contrary to earlier observations in literature. However, since it was able to reduce viable cell populations of HCT116 at $48 \mathrm{~h}$ post-transfection, it may imply that cell death and growth arrest following down-regulation of Id2 may occur via a different mechanism so further studies should be carried out to address this inconsistency. In conclusion, Id 1 and Id 3 could provide potential therapeutic properties to cure colonic cancers since the regulation of these proteins could potentially induce apoptosis in colon cancers.

\section{Acknowledgement}

The author wishes to acknowledge the contribution made by the gene regulation laboratory, and the molecular medicine group of the University of Essex.

\section{References}

Askew, D. S., Ashmun, R. A., Simmons, B. C., \& Clevaland, J. L. (1991). Constitutive c-myc expression in an IL-3-dependent myeloid cell line suppresses cell cycle arrest and accelerates apoptosis. Oncogene, 6, 1915-1922.

Fong, S., Debs, R. J., \& Desprez, P. Y. (2004). Id genes and proteins as promising targets in cancer therapy. Trends Molecular Medicine, 10, 387-92. http://dx.doi.org/10.1016/j.molmed.2004.06.008

Gray, M. J., Dallas, N. A., Van Buren, G., Xia, L., Yang, A. D., Somcio, R. J., Gaur, P., Mangala, L. S., Vivas-Mejia, P. E., Fan, F., Sanguino, A. M., Gallick, G. E., Lopez-Berestein, G., Sood, A. K., \& Ellis, L. M. (2008). Therapeutic targeting of Id2 reduces growth of human colorectal carcinoma in the murine liver. Oncogene, 27, 7192-7200. http://dx.doi.org/10.1038/onc.2008.356

Hiebert, S. W., Packam, G., Strom, D. K., Haffner, R., Oren, M., Zambetti, G., \& Cleveland, J. K. (1995). E2F-1:DP-1 induces p53 and overrides survival factors to trigger apoptosis. Molecular and Cell Biology, 15, 6864-68774.

Israel, M. A., Hernandez, M-C., Florio, M., Andres-Barquin, P., Mantani, A., Carter, J. H., \& Julin, C. M. (1999). Id gene expression as a key mediator of tumour cell biology. Cancer Research, 59, 1726-1730.

Lasorella, A., Iavarone, A., \& Israel, M. A. (1996). Id2 specifically alters regulation of the cell cycle by tumor suppressor proteins. Molecular and Cell Biology, 16, 2570-2578.

Lin, C. Q., Singh, J., Murata, K., Itahana, Y., Parrinello, S., Liang, S. H., Gillett, C. E., Campisi, J., \& Desprez, P. Y. (2000). A role for Id-1 in the aggressive phenotype and steroid hormone response of human breast cancer cells. Cancer Research, 60, 1332-1340.

Lyden, D., Young, A. Z., Zagzag, D., Yan, W., Gerald, W., O'Reilly, R., Bader, B. L., Hynes, R. O., Zhuang, Y., Manova, K., \& Benezra, R. (1999). Id1 and Id3 are required for neurogenesis, angiogenesis and vascularization of tumour xenografts. Nature, 401, 670-677. 
http://dx.doi.org/10.1038/44334

Nishiyama, K., Takaji, K., Kataoka, K., Kurihara, Y., Yoshimura, M., Kato A., Ogawa, H., \& Kurihara, H. (2005). Id1 gene transfer confers angiogenic property on fully differentiated endothelial cells and contributes to therapeutic angiogenesis. Circulation, 112, 2840-2850. http://dx.doi.org/10.1161/CIRCULATIONAHA.104.516898

Norton, J. D. (2000) Id helix-loop-helix proteins in cell growth, differentiation and tumourigenesis. Journal of Cell Science, 113, 3897-3905.

Ruzinova, M. B., Schoer, R. A., Gerald, W., Egan, J. E., Pandolfi, P. P., Rafii, S., Manova, K., Mittal, V., \& Benezra, R. (2003). Effect of angiogenesis inhibition by Id loss and the contribution of bone marrow derived endothelial precuresor cells in spontaneous murine tumors. Cancer Cell, 4, 277-289. http://dx.doi.org/10.1016/S1535-6108(03)00240-X

Sakurai, D., Tsuchiya, N., Yamaguchi, A., Okaji, Y., Tsuno, N. H., Kobata, T., Takahashi, K. \& Tokunaga, K. (2004). Crucial Role of Inhibitor of DNA Binding/Differentiation in the Vascular Endothelial Growth Factor-Induced Activation and Angiogenic Processes of Human Endothelial Cells. Journal of Immunology, 173, 5801-5809. http://dx.doi.org/10.4049/jimmunol.173.9.5801

Sikder, H. S., Meghann, K. D., Shariff, D., Byungwoo, R., \& Alani, R. M. (2003). Id proteins in cell growth and tumourigenesis. Cancer Cell, 3, 525-530. http://dx.doi.org/10.1016/S1535-6108(03)00141-7

Tsuchiya, T., Okaji, Y., Tsuno, N.H., Sakurai, D., Tsuchiya, N., Kawai, K., Yazawa, K., Asakage, M., Yamada, J., Yoneyama, S., Kitayama, J., Osada, T., Watanabe, T., Tokunaga, K., Takahashi, K. \& Nagawa, H. (2005). Targeting Id1 and Id3 inhibit peritoneal metastasis of $\begin{array}{lllll}\text { gastric cancer. } & \text { Cancer } & \text { Science, } & \text { 784-790. }\end{array}$ http://dx.doi.org/10.1111/j.1349-7006.2005.00113.x

Wagner, A. J., Kokontis, M. J., \& Hay, N. (1994). Myc-mediated apoptosis requires wild-type p53 in a manner independent of cell cycle arrest and the ability of p53 to induce p21 (WAF-1/CIP-1). Genes and Development, 8, 2817-2830. http://dx.doi.org/10.1101/gad.8.23.2817

Wilson, J. W., Deed, R. W., Inoue, T., Balzi, M., Becciolini, A., Faraoni, P., Potten, C. S., \& Norton, J. D. (2001). Expression of Id helix-loop-helix proteins in colorectal adenocarcinoma correlates with p53 expression and mitotic index. Cancer Research, 61, 8803-8810.

\section{Copyright Disclaimer}

Copyright for this article is retained by the author(s), with first publication rights granted to the journal.

This is an open-access article distributed under the terms and conditions of the Creative Commons Attribution license (http://creativecommons.org/licenses/by/3.0/). 